\title{
Influence of Personality Traits on the Continued Use of Fitness Apps
}

\author{
Moayad Alshawmar \\ Worcester Polytechnic Institute \\ malshawmar@wpi.edu
}

\author{
Bengisu Tulu \\ Worcester Polytechnic Institute \\ bengisu@wpi.edu
}

\author{
Adrienne Hall-Phillips \\ Worcester Polytechnic Institute \\ ahphillips@wpi.edu
}

\begin{abstract}
While fitness apps show promise to improve people's health and well-being, studies have indicated a high dropout rate among their users. This study uses the expectation confirmation model (ECM) to examine post-adoption factors affecting continued use or dropout among users of fitness apps, with a specific focus on the impact of users' personality traits (the "big five" traits) on the ECM model variables. We present our theoretical model and the results of our survey with 129 participants. We confirm that satisfaction, perceived usefulness, and confirmation of expectations resulting from use of fitness apps influence the continued use of the apps. Moreover, we show that conscientiousness and neuroticism, as traits, positively influence perceived usefulness. This study increases our understanding of the factors impacting continued use of fitness apps.
\end{abstract}

\section{Introduction}

The performing of consistent physical activity such as walking, running, and working out provides several physical, mental, and emotional benefits, such as preventing chronic diseases, improving memory and brain function, and reducing anxiety and depression [1]. However, people may not maintain consistent physical activity due to lack of time, motivation, and knowledge regarding performing physical activity properly [2]. As a result, fitness apps have been developed to guide people and encourage them to maintain regular physical activity [3]. Fitness apps collect users' activity data and analyze it to help users achieve their activity goals [4].

Reports have shown that $58 \%$ of smartphone users have at least one health and fitness app on their devices [5], and the number of downloaded fitness apps increased by 330\% from 2014 to 2017 [6]. Using fitness apps, people can actualize various affordances such as having their goals promoted (by being reminded), comparing themselves to others, and being coached [7]. When these affordances are actualized, people may develop healthy habits, become aware of their health status, and be able to reach their health goals [7].

Despite the potential benefits and high download and usage rates of fitness apps, studies have indicated a high dropout rate after a short period of use [8]. The short period of use has reduced fitness apps' capability to improve users' health and well-being [9]. In fact, health benefits do not appear without repetitive exercise performed for a sufficient time [10]. Studies have discovered factors impacting continued use of apps by users, such as the ease of use [11], design features or functions [4], and motivational elements such as gamification and socialization [12].

While previous studies have increased our understanding of the technical and functional factors that lead users to continue using fitness apps, few studies have investigated the influence of users' perceptions on their behaviors conducive to continuing their use of the apps [13]. Previous studies on perceptions applied different theoretical models, such as the extended unified theory of acceptance and use of technology model (UTAUT2) [14], the technology acceptance model (TAM) $[15,16]$ and the expectation-confirmation model (ECM) [8]. While the UTAUT2 and the TAM focus on pre-consumption variables, the ECM focuses primarily on postconsumption variables [17], which is necessary for explaining continued use.

The ECM posits that after an initial acceptance of technology, users' intention to continue using a technology is determined by their satisfaction with their technology use and the perceived usefulness of the technology [17]. Meanwhile, users' perceived usefulness and satisfaction with a technology are influenced by their confirmation of prior expectations of the technology. Hence, the ECM is useful for uncovering factors impacting users' intention to continue using fitness apps [13].

Previous research on the continued use of various technologies found that users' personality traits influence the ECM variables [18-20]. However, in the context of fitness apps, where the goal of use is to improve one's well-being, the influence of users' personality traits on the ECM variables is 
understudied. Studying the influence of users' personality traits on the ECM in the context of fitness apps can help us understand the factors influencing the continued use of fitness apps. Given that continued use is essential to benefit from using fitness apps to improve users' well-being, any insights into this behavior can help researchers improve the design of technology-based lifestyle interventions involving physical activity.

While many personality traits have been examined in personality literature, the Five-Factor Model (FFM) is the most accepted one [21]. The FFM, identifying the big five traits, categorizes human personality into five dimensions: agreeableness, conscientiousness, extraversion, neuroticism, and openness to experience. Therefore, this research will uncover the impact of users' personality traits on the continued use of fitness apps focusing on the big five.

\section{Background}

\subsection{Fitness apps and continued use}

Long-term use of fitness apps is essential to improve users' health and well-being [4]. According to a systematic review of mHealth apps, including fitness apps, the benefits of the apps start to appear during the 4th through the 6th months of use [9]. However, previous studies have found that such longterm use is rare among mHealth app users in general and fitness app users in particular [9, 22]. Previous studies on mHealth and fitness apps have uncovered various aspects impacting users' continued use, such as technical issues in the apps [23], design preference [24], and motivational features [25-27]. Moreover, users' perception pre and post their adoption of a technology can play a significant role in their behaviors in accepting and using the technology [28]. Several IS models such as the TAM [29], the UTAUT2 [30], and the ECM [17] have become widely accepted in IS domain and found to be useful in predicting users' intention to adopt and utilize technology [3133].

In mHealth and fitness app studies, these IS models have been used and extended to discovers factors impacting users' intention to adopt and continue using the apps. For example, when Yuan, et al. [14] applied the UTAUT2 model with some extensions, they found that factors such as users' expected performance, hedonic motivations, and app prices could also predict users' intention to adopt fitness apps. Extending the TAM model, Beldad and Hegner [15] found that variables such as perceived ease of use, perceived usefulness, and injunctive social norms (influenced by social pressure) were essential factors in motivating users to use the apps. Moreover, Beldad and Hegner [15] also found that users' trust in the app developer and descriptive social norms (influenced by what people usually do) are not essential factors. Another study found that optimism, innovativeness, discomfort, and insecurity affected the TAM acceptance model in the use of dietary and fitness apps [16].

Applying the TAM and the ECM at the same time on adult Korean users of health and activity apps, Cho [8] confirmed that the models' predictors of perceived usefulness, perceived ease of use, confirmation, and satisfaction notably impacted the users' intention to continue using health and activity apps. The study also found that ease of use influenced users' satisfaction with the apps while perceived usefulness did not [8]. Chiu, et al. [34] applied the ECM and included factors from the Investment Model (IM) that illustrate human commitment to their relationships with other humans and extended later to objects, namely satisfaction, investment size, and quality of alternatives. The study found that all ECM and some IM variables, such as investment size and commitment, influenced users' continued use of mHealth and fitness apps [34]. To study the intention of young Chinese adults (18 to 30 years old) to continue using fitness apps, the authors extended the ECM with variables such as confirmed ease of use, entertainment, social connection, and fitness achievement [35]. The study revealed that all the variables except entertainment influenced users' continued usage [35] Furthermore, the authors found that users' level of achievement did not lead them to be more satisfied with the apps [35].

Previous studies have contributed to the literature on the continued use of mHealth and fitness apps by uncovering factors impacting users' intention to adopt and continue using fitness apps [8, 14-16, 34, 35]. They have applied different technology use and acceptance models along with some extensions. In this study, we add to the fitness app literature by uncovering the impact of users' personality traits on their continued use of the apps using the Expectation Confirmation Model (ECM). We selected the ECM due to its primary focus on users' post-adoption behaviors [17].

Previous studies using the ECM have relied primarily on asking users about their future intention to use technology to indicate their continued use of it $[8,34]$. This study examined actual dropout and current fitness app users to determine continued use. This was achieved by surveying users who used the app and then stopped, as well as existing users. Exploring actual use is important because users' intention to continue their use is based on users' best 
expectation of their future behaviors, while the reality may not be the same as those expectations [36].

Furthermore, this study also investigated the impact of the big five personality traits on the ECM. The big five personality traits influence users' perception and behaviors in using many technologies, including mHealth and fitness apps [37-39]. To the best of our knowledge, no study has examined the impact of the big five personality traits on the ECM in the context of fitness apps.

\subsection{The Expectation-Confirmation Model (ECM)}

The Expectation-Confirmation Model (ECM) was created by Bhattacherjee [17] to address factors impacting users' intentions to continue using an IT artifact. The ECM was developed based on a wellknown consumer behavior theory, the expectationconfirmation theory (ECT) that illustrates the process of consumers' decisions in buying and rebuying a product (good or service) [40]. Bhattacherjee [17] argued that similar to consumers' repeated purchasing decisions, IT users' continued use of a technology is influenced by the degree of the perceived usefulness and satisfaction users experience while using it. At the same time, the degree of perceived usefulness and satisfaction are influenced by users' confirmation of their previous expectations regarding the use of the technology [17] (see Figure 1).

The ECM has been adopted widely in IS research aiming to understand users' continuing usage behavior in various technology contexts, such as e-learning [41], electronic commerce [42, 43], wearable devices [44], and mHealth and fitness apps [8, 34]. Our study contributes to the limited knowledge on fitness apps by examining the following hypotheses adopted from the ECM for application to fitness apps. Thus, we hypothesize:

H1 Users' extent of confirmation is positively associated with their perception of the usefulness of fitness apps.

H2 Users continuance use of fitness apps is positively associated with their perception of the usefulness of fitness apps.

H3 Users' perception of the usefulness of fitness apps is positively associated with their satisfaction with their use of the fitness apps.

H4 Users' extent of confirmation is positively associated with their satisfaction with their use of fitness apps.

H5 Users' level of satisfaction with their initial use of fitness apps is positively associated with their continued use of fitness apps.

\subsection{Big five personality traits}

The big five personality traits considers a set of traits that characterize human personality into five major characteristics; with the understanding that an individual will tend to have some of them more than others [45]. Human personality traits are not theoretically limited to the big five traits, but the big five were discovered empirically [21] and have been found useful in describing human differences at a fairly abstract level [21]. The big five traits are extraversion, agreeableness, conscientiousness, neuroticism, and openness to experience.

2.3.1. Extraversion. People who score high on extraversion personality traits are more likely to be socialized, outgoing, optimistic, and energetic [45]. Their desire to maintain a social image motivates them to behave toward enhancing that image [18]. Therefore, extraverted employees perform effectively in jobs that required human interaction, such as sales and management [46]. Extraverted users of social networking sites socialize more than other personalities, motivating them to continue their use on these sites [20]. We argue that since many fitness apps enable receiving social feedback from others (e.g., leaderboards, rankings, likings, commenting, and sharing/posting activities), extraverted users will most likely be motivated to continue using these apps. Since continued use is likely result in more fitness activity, they would also perceive these apps as useful. This leads to the following hypothesis:

H6 Extraversion is positively associated with the perceived usefulness of fitness apps.

2.3.2. Agreeableness. People who score high on agreeableness are more likely to be tolerant, courteous, sympathetic, forgiving, and less demanding [47].. Agreeable employees are more productive when their job involves cooperating with other employees [48]. Moreover, they are more likely to be active utilizers when the technology enables cooperation and task accomplishment [18]. Hence, agreeable students perceived the usefulness of using the university's bulletin board system and collaborative classroom system $[18,49]$. We argue that since features of fitness apps (e.g., competitions, activity reports of others, other's profile pages) could facilitate collaborative exercise, aggregable users will most likely use and receive the benefits from these features, hence perceive the app's usefulness. Thus, we hypothesize:

H7 Agreeableness is positively associated with perceived usefulness with fitness apps. 
2.3.3. Conscientiousness. People who score high on conscientiousness tend to be more organized, efficient, and motivated to achieve [47]. Thus, it is no wonder that conscientious people are excellent at following physical activity instructions [50]. Furthermore, in using a work-related system, conscientious people have been discovered to have the intention to use the system, perceive the system's usefulness, become effective in using it $[18,51]$, and have the intention to continue using it $[49,52]$. Thus, we argue that conscientious users of fitness apps are more likely to perceive fitness apps' usefulness. Therefore, we hypothesize:

H8 Conscientiousness is positively associated with the perceived usefulness of fitness apps.

2.3.4. Neuroticism. Neuroticism (also reversed and named Emotional Stability) is a personality trait determined by people's level of control over their emotions [53]. People who score high on neuroticism are more likely to feel anxious, insecure, moody, and easily upset [53]. At the same time, those who score low on neuroticism are more likely to have stable emotions and are less stressed [53]. Neurotic employees were less satisfied with their jobs [54] and career accomplishments [55]. In using technology, neurotics students were found to negatively relate to using and perceiving a classroom system's usefulness [51]. Neurotic students were also found to experience anxiety more than other students when using computers [56]. Moreover, among Facebook users, neurotics perceived Facebook's usefulness negatively [19]. Consequently, we argue that due to neurotics' unoptimistic and pessimistic view of life as supported by previous studies, neurotics will not perceive an app's usefulness, and neither will they confirm its expected value. Thus, we hypothesize:

H9 Neuroticism is negatively associated with the perceived usefulness of fitness apps.

H10 Neuroticism is negatively associated with the users' extent of confirmation of fitness apps.

2.3.5. Openness to Experience. People who score high on openness to experience are intellectual, openminded, imaginative, curious, and willing to explore new ideas [47]. Therefore, employees with openness trait are found to be more willing to accept changes and their curiosity lead them to try new things such as using a computer but with caution related to the expected risk [57]. In using mHealth apps, studies found that people who are open to experience are adopters, active utilizers, and long term users of several mHealth apps such as self-management apps for people with hypertension [37], mindfulness and relaxation apps for cancer [39], and self-management apps for patients with diabetes [38]. We argue that since people with openness to experience trait are willing to try new things, this trait would lead them to try fitness apps and perceive their usefulness. Hence, we hypothesize:

H11 Openness to experience is positively associated with the perceived usefulness of fitness app use.

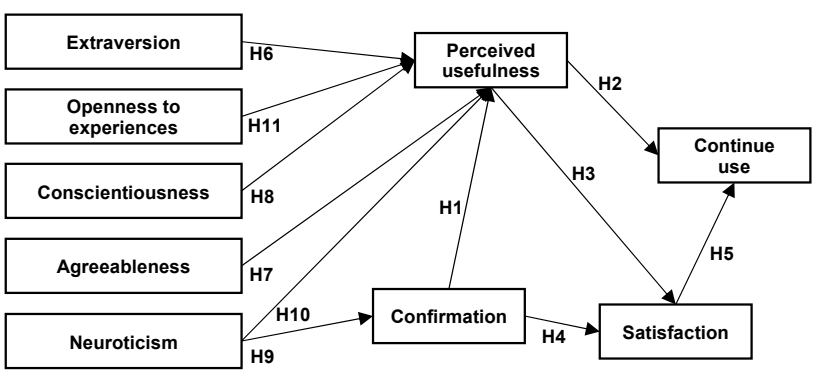

Figure 1. Research model.

\section{Methodology}

\subsection{Survey instrument}

This study adopted its survey from previous mHealth and fitness apps studies that applied ECM [34] and a widely used short version of the big five personality traits [58]. The survey instrument consists of six sections: (1) a big five personality traits (two items for each trait), (2) user usage status, (3) satisfaction (four items), (4) perceived usefulness (four items), (5) confirmation (three items), and (6) demographic information, as shown with details in Table 1. ECM questions that capture users' intention to continue their use of the app were replaced with questions that target existing continued and dropout users. All questions were accompanied by multiple answer choices and allowed text entry when applicable. All items were measured on a seven-point Likert scale, ranging from strongly disagree (1) to strongly agree (7).

\subsection{Participants and procedure}

We conducted this study using Qualtrics online survey platform, during the period from 04/10/2021$05 / 15 / 2021$. Before distributing the survey, we ran a pilot test with seven graduate and undergraduate students using talk-through technique to validate the survey. Next, through a US university email list and social media targeting US users, participants were invited to voluntarily complete an online survey. The email and social media messages specified two criteria for the participants' eligibility: they were (1) adults (18 and above) and (2) users of any fitness app (either 
current users or dropout users). Examples of fitness apps, such as Apple Health, Samsung Health, MyFitnessPal, Fitbit, and NIKE + Run Club were given in the invitation email for clarification. In addition, participants were informed they had a chance to win a $\$ 200$ prize upon completing the survey. The survey was approved by the Institutional Review Board (IRB) at a US university. A total of 175 questionnaires were collected, 27 of which had incomplete responses, and 19 of which were from users who indicated that they had never used a fitness app before. Consequently, we were left with 129 complete responses.

\section{Table 1. Survey items.}

\begin{tabular}{|c|}
\hline Survey sections and questions \\
\hline Demographic information \\
\hline Gender \\
\hline Age \\
\hline User usage status \\
\hline Current users and dropout users \\
\hline Used app name \\
\hline Frequency of use (weekly) \\
\hline Usage duration \\
\hline Satisfaction [34] \\
\hline Overall experience with the use of the fitness app \\
\hline Perceived usefulness [34] \\
\hline Perceived improvement in doing exercise \\
\hline Perceived effectiveness in doing exercise \\
\hline Perceived productivity in doing exercise \\
\hline Confirmation [34] \\
\hline Experience was better than expected \\
\hline Service level was better than expected \\
\hline Overall, most expectation were confirmed \\
\hline Ten items-Personality traits [58] \\
\hline 1. Extraverted, enthusiastic. \\
\hline 2. Critical, quarrelsome (R). \\
\hline 3. Dependable, self-disciplined. \\
\hline 4. Anxious, easily upset (R). \\
\hline 5. Open to new experiences, complex. \\
\hline 6. Reserved, quiet (R). \\
\hline 7. Sympathetic, warm. \\
\hline 8. Disorganized, careless (R). \\
\hline 9. Calm, emotionally stable. \\
\hline 10. Conventional, uncreative (R). \\
\hline $\begin{array}{l}\text { Personality scale scoring ("R" means reverse-scored } \\
\text { items): Extraversion: }(1,6) \text { Agreeableness: }(2,7) \text {; } \\
\text { Conscientiousness; }(3,8) \text {; Emotional Stability: }(4,9) \text {; } \\
\text { Openness to Experiences: }(5,10) \text {. }\end{array}$ \\
\hline
\end{tabular}

\subsection{Data analysis}

Partial least squares (PLS), structural equation modeling (SEM) was employed to analyze the quantitative data using SmartPLS 3.3.3 and SPSS to uncover the distribution of personality traits. The PLS approach was selected due to its usefulness in a study still in its exploratory stage, aims to discover and predict, has small sample size, and the research model's being complex [59]. Furthermore, as Chin, et al. [60] recommended, the sample size for PLS must be either larger than ten times the scale with the largest number of formative indicators or ten times the largest number of the structural paths [61]. The model presented in this study satisfies these two criteria by containing 11 paths and no more than four indicators for each scale.

\section{Results}

\subsection{Study sample}

The 129 respondents consisted of slightly more males $(55 \%)$. The majority of our participants were between 18 - 24 years old (44\%) or between 25-34 years old $(41 \%)$. Most of our participants were current users of the apps $(75 \%)$, and half of them used fitness apps for more than 12 months $(50 \%)$. About a quarter of our participants were dropout users (24\%), and most of them used fitness apps for less than three months before they stopped using them (65\%). Most of the participants in both groups were using these apps daily (current users 42\%) and (dropout users 40\%). Almost all of the participants across both groups (97\%) were using the apps at least once a week. Few participants $(3 \%)$ did not indicate a clear answer of their use, such as "I use it when I do exercise.". Both groups' personality traits were distributed by openness to experience with the highest mean (current users' mean 5.89 and dropout users' mean 5.78) and neuroticism with the lowest mean (current users' mean 4.29 and dropout users' mean 3.66). Table 2 summarizes our sample characteristics.

\subsection{Scale reliability and validity}

We began the examination by evaluating the model indicator reliability, internal reliability, convergent validity, and discriminant validity. Indicators with outer loadings lower than 0.5 were dropped. In our model, the ECM indicators of perceived usefulness, confirmation, and satisfaction all satisfied the criteria; hence, the ECM items were kept in the model. For the big five personality traits, one item for each was dropped from agreeableness, conscientiousness, openness to experiences, and neuroticism due to having lower outer loading results. Internal reliability was evaluated using composite reliability indicated by the fact that each construct was greater than 0.7 and below 0.95 as recommended by Hair, et al. [62] (see Table 3). 
Table 2. Characteristics of study sample.

\begin{tabular}{|lll|}
\hline Question & $\begin{array}{l}\text { Dropout users } \\
\text { (N=32) }\end{array}$ & $\begin{array}{l}\text { Current users } \\
\text { (N=97) }\end{array}$ \\
Gender & $\%$ & $\%$ \\
Man & $63 \%$ & $54 \%$ \\
Woman & $34 \%$ & $46 \%$ \\
Others & $3 \%$ & $0 \%$ \\
Age & $\%$ & $\%$ \\
18-24 years & $47 \%$ & $39 \%$ \\
25-34 years & $50 \%$ & $43 \%$ \\
35-44 years & $3 \%$ & $12 \%$ \\
45-54 years & $0 \%$ & $2 \%$ \\
55-64 years & $0 \%$ & $3 \%$ \\
Frequency of use & $\%$ & $\%$ \\
Daily & $40 \%$ & $42 \%$ \\
4-6 times a week & $15 \%$ & $27 \%$ \\
2-3 times a week & $28 \%$ & $21 \%$ \\
Once a week & $12 \%$ & $6 \%$ \\
Other & $3 \%$ & $3 \%$ \\
Duration of use & $\%$ & $\%$ \\
Less than 1 month & $34 \%$ & $3 \%$ \\
1-3 months & $31 \%$ & $25 \%$ \\
4-6 months & $6 \%$ & $12 \%$ \\
7-9 months & $6 \%$ & $8 \%$ \\
10-12 months & $3 \%$ & $3 \%$ \\
12+ & $18 \%$ & $50 \%$ \\
Personality trait & Mean & Mean \\
Agreeableness & 4.84 & 5.57 \\
Openness & 5.78 & 5.89 \\
Conscientiousness & 5.28 & 4.93 \\
Neuroticism & 3.66 & 4.29 \\
Extraversion & 4.26 & 5.15 \\
\hline
\end{tabular}

Table 3. Construct reliability and validity.

\begin{tabular}{|l|l|l|}
\hline Variable & $\begin{array}{l}\text { Composite } \\
\text { Reliability }\end{array}$ & $\begin{array}{l}\text { Average Variance } \\
\text { Extracted (AVE) }\end{array}$ \\
\hline PU & 0.926 & 0.758 \\
\hline SAT & 0.938 & 0.791 \\
\hline CON & 0.892 & 0.734 \\
\hline E & 0.863 & 0.762 \\
\hline
\end{tabular}

Notes: CON (confirmation), PU (perceived usefulness), SAT (satisfaction), and E (Extraversion)

Convergent validity was assessed using the average variance extracted, and each construct was greater than 0.5 , which indicates that the construct explains a minimum of $50 \%$ of the variance of its items [62]. Discriminant validity was evaluated using the Heterotrait-Monotrait Ratio (HTMT), which suggests that the HTMT value must be below 0.90 to establish discriminant validity between two reflective constructs [62]; this was the case in this study (see Table 4).
Table 4. Heterotrait-monotrait ratio (HTMT).

\begin{tabular}{|l|l|l|l|l|l|l|l|l|}
\hline & $\mathrm{A}$ & $\mathrm{C}$ & $\mathrm{CON}$ & $\mathrm{E}$ & $\mathrm{CU}$ & $\mathrm{N}$ & $\mathrm{O}$ & $\mathrm{PU}$ \\
\hline $\mathrm{C}$ & .166 & & & & & & & \\
\hline $\mathrm{CON}$ & .070 & .066 & & & & & & \\
\hline $\mathrm{E}$ & .061 & .114 & .169 & & & & & \\
\hline $\mathrm{CU}$ & .120 & .089 & .469 & .271 & & & & \\
\hline $\mathrm{N}$ & .247 & .189 & .102 & .261 & .156 & & & \\
\hline $\mathrm{O}$ & .109 & .142 & .108 & .433 & .043 & .140 & & \\
\hline PU & .037 & .105 & .750 & .212 & .515 & .059 & .132 & \\
\hline SAT & .050 & .047 & .858 & .194 & .424 & .101 & .059 & .610 \\
\hline
\end{tabular}

Notes: CON (confirmation), PU (perceived usefulness), SAT (satisfaction), CU (continued use), E (extraversion), A (agreeableness), C (Conscientiousness), $\mathrm{N}$ (neuroticism), and $\mathrm{O}$ (openness).

\subsection{Hypothesis testing}

We tested the model by calculating the coefficient of determination $\mathrm{R}^{2}$ and the blindfolding-based crossvalidated redundancy $\mathrm{Q}^{2}$ to describe the amount of variance explained by the variables and assess the path model's predictive accuracy [62]. We then calculated path coefficients by running a bootstrapping with 500 subsamples to explain the relationship between the model variables. The results of the model evaluation are presented in Figure 2 and Table 5.

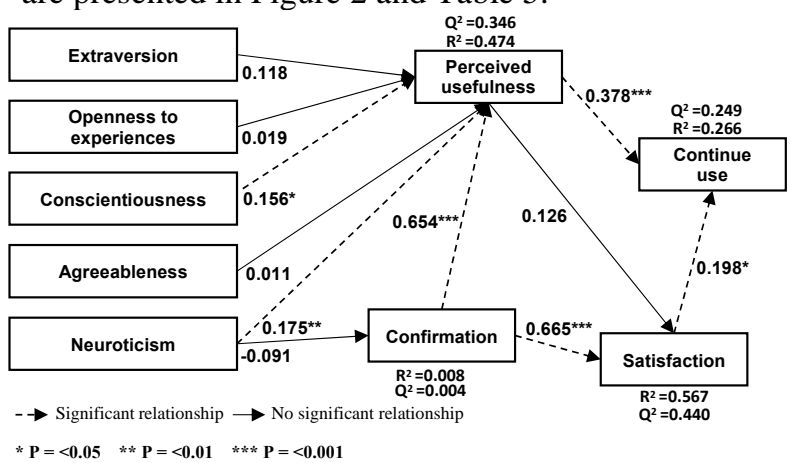

Figure 2. Research model evaluation.

Table 5. Results of hypothesis.

\begin{tabular}{|l|l|l|}
\hline Hypothesis & $\begin{array}{l}\text { Path } \\
\text { Coefficient }\end{array}$ & P Values \\
\hline H1: CON $\rightarrow$ PU (S) & 0.654 & 0.000 \\
\hline H2: PU $\rightarrow$ CU (S) & 0.378 & 0.000 \\
\hline H3: PU $\rightarrow$ SAT (NS) & 0.126 & 0.085 \\
\hline H4: CONF $\rightarrow$ SAT (S) & 0.665 & 0.000 \\
\hline H5: SAT $\rightarrow$ CU (S) & 0.198 & 0.024 \\
\hline H6: E $\rightarrow$ PU (NS) & 0.118 & 0.141 \\
\hline H7: A $\rightarrow$ PU (NS) & 0.011 & 0.873 \\
\hline H8: C $\rightarrow$ PU (S) & 0.167 & 0.031 \\
\hline H9: N $\rightarrow$ CONF (NS) & -0.083 & 0.306 \\
\hline H10: N $\rightarrow$ PU (S) & 0.175 & 0.014 \\
\hline H11: O $\rightarrow$ PU (NS) & -0.019 & 0.229 \\
\hline
\end{tabular}

Notes: abbreviations are mentioned above in Table 4. 
The $\mathrm{R}^{2}$ values of the variables presented in Figure 2 (perceived usefulness $R^{2}=0.474$, satisfaction $R^{2}=$ 0.567 , and continue use $\mathrm{R}^{2}=0.266$ ) indicate a moderate explanatory power by the pointed variables [62]. The $\mathrm{R}^{2}$ for the confirmation is too low $\left(\mathrm{R}^{2}=0.008\right)$, which indicates that the pointed variable (neuroticism) has low power in explaining confirmation [62]. The $\mathrm{Q}^{2}$ values observed for perceived usefulness $\left(Q^{2}=0.346\right)$, satisfaction $\left(Q^{2}=\right.$ $0.440)$, and continued use $\left(Q^{2}=0.249\right)$ indicate medium predictive relevance in our model. The $\mathrm{Q}^{2}$ value for conformation is too low $\left(\mathrm{Q}^{2}=0.004\right)$ which indicates lack of predictive relevance between confirmation and neuroticism. The results of the ECM hypotheses regarding fitness apps focusing on actual users (current vs. dropout users) show that four of the ECM hypotheses that explain the influence of confirmation to perceived usefulness (H1), perceived usefulness to continue use $(\mathrm{H} 2)$, confirmation to satisfaction (H4), and satisfaction to continue use (H5) were confirmed with a positive relationship. On the other hand, the influence of perceived usefulness to satisfaction (H3) was not supported in our data.

Our analysis of the impact of the big five traits on the ECM showed that conscientiousness is a positive significant predictor of perceived usefulness, aligning with our hypothesis (H8). At the same time, neuroticism (the opposite of emotional stability) has a positive relationship with perceived usefulness, contradicting our hypothesis (H10). Personality traits such as extraversion, openness, and agreeableness did not have any significant effect on the ECM constructs in our data. Overall, four (out of five) of the ECM and one (out of five) of the personality traits hypotheses were supported. The result for neuroticism was not aligned with the hypothesis (H10) but presented with a positive significant impact on perceived usefulness.

\section{Discussion}

This study aimed to uncover the impact of users' personality traits on the continued use of fitness apps, using the ECM and the big five personality traits. Focusing on actual users who are either continuing to use fitness apps (current users) or used them for a while but decided to stop using them after their experience (dropouts), our results support the ECMbased hypotheses that users' perceived usefulness, satisfaction, and confirmation of what was expected are predictors of users' actual continuing use of the apps. However, our results did not support the ECM hypotheses that emphasize a relationship between perceived usefulness and satisfaction. Furthermore, perceived usefulness presented with higher influence on continue use compared to other published ECM studies $[8,34]$. This indicates that some fitness app users may continue their use because of perceived usefulness of the apps even though they are not fully satisfied with their overall experience. User satisfaction is explained by confirmation of expectations rather than users' perceptions of usefulness. Similar results have been reported by a previous fitness app study [8] and studies of a variety of other technologies [63-66].

Our results also indicate that most dropout users $(65 \%)$ had not exceeded three months of use of their apps. When another previous fitness app study investigated the ECM but recruited long-term (majority $1-3$ years) users as participants [34], they found that perceived usefulness has a positive relationship with satisfaction. Based on our data, testing the ECM on long-term users may not reveal an accurate result because users who dropped out earlier would be excluded from the study. This could explain why our results of the relationship between perceived usefulness and satisfaction are aligned with the other fitness app study that used ECM and did not specify participants' duration of use [8].

The results on the relationship between the big five personality traits and the ECM indicate that such personality traits influence users continued use of fitness apps. We found that conscientiousness influences users' perception of perceived usefulness positively. People with conscientiousness personality traits are known to be high achievers [47]; hence, it's not surprising that participants with high levels of conscientiousness perceived the apps' usefulness. On the other hand, neuroticism (the opposite of emotional stability) presented a significant positive result with the perceived usefulness of the apps. This was unexpected because neurotic people are known to have negative perceptions when interacting with things in their lives [53]. However, the results of neuroticism and the missing influence of the other personality traits on the ECM might result from the study's limitations. This study depends on a single-item personality measurement on a small population. The single item personality measurements on a small sample size might not represent all big five traits equally.

This research contributes to the literature on continued use of fitness apps by confirming the importance of users' positive confirmation of expectation, perceived usefulness, and satisfaction for their continued use of fitness apps. Further, their personality traits might influence their perception of the apps, leading them to discontinue their use. Finally, our results further support the literature findings that there are indeed many dropout users of fitness apps within a short period after the first use. 
This research also has practical contributions for development of fitness apps. Our results suggest fitness app developers should continually remind users of the potential benefits of app use, which can increase perceptions of usefulness. The developers should also ensure that users' expectations of the apps are aligned with what the apps could provide to them. Bhattacherjee [17] argues that gaining users' satisfaction becomes harder when users have higher expectations of technology. Uncovering users' expectation can be achieved by asking them about their expectations of the app before using the app. Moreover, since users' personality traits may influence their perceptions and behaviors, developers could treat users based on their personality traits when trying to improve their perceptions of the apps' usefulness. Considering all these together, developers will enhance users' satisfaction with the apps that will consequently lead them to continue their use.

\section{Limitation and future research}

As with all research, our study has some limitations. We used a short version of the big five traits to assess the users' personality traits, and we deleted some items due to low reliability. However, to some extent, the short version results could reflect the results that would have been obtained by the long version, as suggested in previous research [67]. To avoid this, future research may use the extended versions of personality trait assessment, such as the 240-item NEO personality inventory [68] or the IPIP 100-items [69], or utilize other shorter personality test such as the 50-item [69] scales as a previous study have indicated its adequate reliability and discernment validity [51].

We included users who have been using the apps for less than three months at the time of the survey as current users and considered them as continuing users due to our small sample size. This may have impacted the accuracy in identifying continuing users, as our results indicate that most dropout users had not exceeded three months of use. However, short-term users (for less than three months) accounted for only $25 \%$ of the current users (97 users), and we do not expect all of them to stop their use of the apps.

Finally, our hypotheses are built on the assumption that the fitness apps used by participants are similar to some degree and users have a common goal for using them, which is to improve their fitness. However, this might not be the case for users of various types of fitness apps (e.g., MyFitnessPal app can be used for diet and exercise tracking). Other factors such as technical problems, design preferences, goals of use, and app use patterns could impact users' continued use. Thus, future research could investigate whether other factors with users' personality traits involved to form users' decisions to continue using fitness apps.

\section{Conclusion}

In this research, we examined the impact of the big five personality traits on the ECM, a well-known model in literature, to study the continued use of fitness apps. Our results contribute to the fitness app literature by emphasizing that ECM key variables are useful for determining users' continued use, and users' personality traits might influence these variables.

\section{References}

[1] WHO. "Physical activity." https://www.who.int/newsroom/fact-sheets/detail/physical-activity (accessed 2021).

[2] R. Guthold, G. A. Stevens, L. M. Riley, and F. C. Bull, "Worldwide trends in insufficient physical activity from 2001 to 2016: a pooled analysis of 358 population-based surveys with 1.9 million participants," The lancet global health, vol. 6, no. 10, pp. e1077-e1086, 2018.

[3] A. N. Sullivan and M. E. Lachman, "Behavior change with fitness technology in sedentary adults: a review of the evidence for increasing physical activity," Frontiers in public health, vol. 4, p. 289, 2017.

[4] I. Vaghefi and B. Tulu, "The continued use of mobile health apps: insights from a longitudinal study," JMIR mHealth and uHealth, vol. 7, no. 8, p. e12983, 2019.

[5] P. Krebs and D. T. Duncan, "Health app use among US mobile phone owners: a national survey," JMIR mHealth and uHealth, vol. 3, no. 4, p. e101, 2015.

[6] L. Kesiraju and T. Vogels, "Health \& fitness app users are going the distance with record-high engagement," Flurry Blog, 2017.

[7] M. Alshawmar, H. Mombini, B. Tulu, and I. Vaghefi, "Investigating the Affordances of Wellness mHealth Apps," in Proceedings of the 54th Hawaii International Conference on System Sciences, p. 3818.

[8] J. Cho, "The impact of post-adoption beliefs on the continued use of health apps," International journal of medical informatics, vol. 87, pp. 75-83, 2016.

[9] M. S. Marcolino, J. A. Q. Oliveira, M. D'Agostino, A. L. Ribeiro, M. B. M. Alkmim, and D. Novillo-Ortiz, "The impact of mHealth interventions: systematic review of systematic reviews," JMIR mHealth and uHealth, vol. 6, no. 1, p. e23, 2018.

[10] B. G. Berger and A. McInman, "Exercise and the quality of life," Handbook of research on sport psychology, pp. 729-760, 1993.

[11] L. Zhou, J. Bao, and B. Parmanto, "Systematic review protocol to assess the effectiveness of usability questionnaires in mhealth app studies," JMIR research protocols, vol. 6, no. 8, p. e151, 2017. 
[12] J. Hamari, L. Hassan, and A. Dias, "Gamification, quantified-self or social networking? Matching users' goals with motivational technology," User Modeling and User-Adapted Interaction, vol. 28 , no. 1, pp. 3574, 2018.

[13] A.-A. Khalil, A. N. Hidayanto, and H. Prabowo, "Identification of Factor Affecting Continuance Usage Intention of mHealth Application: A Systematic Literature Review," in 2020 4th International Conference on Informatics and Computational Sciences (ICICoS), 2020: IEEE, pp. 1-6.

[14] S. Yuan, W. Ma, S. Kanthawala, and W. Peng, "Keep using my health apps: Discover users' perception of health and fitness apps with the UTAUT2 model," Telemedicine and e-Health, vol. 21, no. 9, pp. 735$741,2015$.

[15] A. D. Beldad and S. M. Hegner, "Expanding the technology acceptance model with the inclusion of trust, social influence, and health valuation to determine the predictors of German users' willingness to continue using a fitness app: A structural equation modeling approach," International Journal of HumanComputer Interaction, vol. 34, no. 9, pp. 882-893, 2018.

[16] M.-F. Chen and N.-P. Lin, "Incorporation of health consciousness into the technology readiness and acceptance model to predict app download and usage intentions," Internet Research, 2018.

[17] A. Bhattacherjee, "Understanding information systems continuance: An expectation-confirmation model," MIS quarterly, pp. 351-370, 2001.

[18] S. Devaraj, R. F. Easley, and J. M. Crant, "Research note- how does personality matter? Relating the fivefactor model to technology acceptance and use," Information systems research, vol. 19, no. 1, pp. 93$105,2008$.

[19] S. Mouakket, "The role of personality traits in motivating users' continuance intention towards Facebook: Gender differences," The Journal of High Technology Management Research, vol. 29, no. 1, pp. 124-140, 2018.

[20] S. Deng, Y. Liu, H. Li, and F. Hu, "How does personality matter? An investigation of the impact of extraversion on individuals' SNS use," Cyberpsychology, Behavior, and Social Networking, vol. 16, no. 8, pp. 575-581, 2013.

[21] J. M. Digman, "Personality structure: Emergence of the five-factor model," Annual review of psychology, vol. 41, no. 1, pp. 417-440, 1990.

[22] L. M. König, G. Sproesser, H. T. Schupp, and B. Renner, "Describing the process of adopting nutrition and fitness apps: behavior stage model approach," JMIR mHealth and uHealth, vol. 6, no. 3, p. e55, 2018.

[23] V. P. Gurupur and T. T. Wan, "Challenges in implementing mHealth interventions: a technical perspective," Mhealth, vol. 3, 2017.

[24] D. Lupton, "Australian women's use of health and fitness apps and wearable devices: a feminist new materialism analysis," Feminist Media Studies, vol. 20, no. 7, pp. 983-998, 2020.
[25] M. Sax, N. Helberger, and N. Bol, "Health as a means towards profitable ends: mHealth apps, user autonomy, and unfair commercial practices," Journal of consumer policy, vol. 41, no. 2, pp. 103-134, 2018.

[26] M. Alshawmar, "A review of the applications of affordance theory in mHealth app research," in Proceedings of the 54th Hawaii International Conference on System Sciences, 2021, p. 3595.

[27] M. Alshawmar and B. Tulu, "Wellness mHealth Apps' Features, Affordances, and Fulfillment of Human Psychological Needs," 2021.

[28] E. Karahanna, D. W. Straub, and N. L. Chervany, "Information technology adoption across time: a crosssectional comparison of pre-adoption and postadoption beliefs," MIS quarterly, pp. 183-213, 1999.

[29] F. D. Davis, "Perceived usefulness, perceived ease of use, and user acceptance of information technology," MIS quarterly, pp. 319-340, 1989.

[30] V. Venkatesh, M. G. Morris, G. B. Davis, and F. D. Davis, "User acceptance of information technology: Toward a unified view," MIS quarterly, pp. 425-478, 2003.

[31] M. Al-Emran, V. Mezhuyev, and A. Kamaludin, "Technology Acceptance Model in M-learning context: A systematic review," Computers \& Education, vol. 125, pp. 389-412, 2018.

[32] M. D. Williams, N. P. Rana, and Y. K. Dwivedi, "The unified theory of acceptance and use of technology (UTAUT): a literature review," Journal of enterprise information management, 2015.

[33] M. A. Hossain and M. Quaddus, "Expectationconfirmation theory in information system research: A review and analysis," Information systems theory, pp. 441-469, 2012.

[34] W. Chiu, H. Cho, and C. G. Chi, "Consumers' continuance intention to use fitness and health apps: an integration of the expectation-confirmation model and investment model," Information Technology \& People, 2020.

[35] X. Zhang and X. Xu, "Continuous use of fitness apps and shaping factors among college students: A mixedmethod investigation," International journal of nursing sciences, vol. 7, pp. S80-S87, 2020.

[36] K.-S. Kim and S.-C. J. Sin, "Selecting quality sources: Bridging the gap between the perception and use of information sources," Journal of Information Science, vol. 37, no. 2, pp. 178-188, 2011.

[37] B. Breil, L. Kremer, S. Hennemann, and J. Apolinário-Hagen, "Acceptance of mHealth apps for self-management among people with hypertension," in GMDS, 2019, pp. 282-288.

[38] J. Su, M. Dugas, X. Guo, and G. G. Gao, "Influence of Personality on mHealth Use in Patients with Diabetes: Prospective Pilot Study," JMIR mHealth and uHealth, vol. 8, no. 8, p. e17709, 2020.

[39] M. Mikolasek, C. M. Witt, and J. Barth, "Adherence to a mindfulness and relaxation self-care app for cancer patients: mixed-methods feasibility study," JMIR mHealth and uHealth, vol. 6, no. 12, p. e11271, 2018.

[40] R. L. Oliver, "A cognitive model of the antecedents and consequences of satisfaction decisions," Journal 
of marketing research, vol. 17 , no. 4, pp. 460-469, 1980.

[41] M.-C. Lee, "Explaining and predicting users' continuance intention toward e-learning: An extension of the expectation-confirmation model," Computers \& Education, vol. 54, no. 2, pp. 506-516, 2010.

[42] S. Devaraj, M. Fan, and R. Kohli, "Antecedents of B2C channel satisfaction and preference: validating ecommerce metrics," Information systems research, vol. 13, no. 3, pp. 316-333, 2002.

[43] C. S. Lin, S. Wu, and R. J. Tsai, "Integrating perceived playfulness into expectation-confirmation model for web portal context," Information \& management, vol. 42, no. 5, pp. 683-693, 2005.

[44] B. Nascimento, T. Oliveira, and C. Tam, "Wearable technology: What explains continuance intention in smartwatches?," Journal of Retailing and Consumer Services, vol. 43, pp. 157-169, 2018.

[45] L. R. Goldberg, "The development of markers for the Big-Five factor structure," Psychological assessment, vol. 4, no. 1, p. 26, 1992.

[46] M. R. Barrick and M. K. Mount, "The big five personality dimensions and job performance: a metaanalysis," Personnel psychology, vol. 44, no. 1, pp. 126, 1991.

[47] P. T. Costa Jr, R. R. McCrae, and D. A. Dye, "Facet scales for agreeableness and conscientiousness: A revision of the NEO Personality Inventory," Personality and individual Differences, vol. 12, no. 9, pp. 887-898, 1991.

[48] M. R. Barrick, M. K. Mount, and T. A. Judge, "Personality and performance at the beginning of the new millennium: What do we know and where do we go next?," International Journal of Selection and assessment, vol. 9, no. 1-2, pp. 9-30, 2001.

[49] C.-S. Ong, "Understanding information systems continuance intention: a five-factor model of personality perspective," 2010.

[50] C. P. McDowell, K. E. Wilson, D. C. Monroe, C. McCrory, R. A. Kenny, and M. P. Herring, "Physical activity partially mediates associations between "Big" personality traits and incident generalized anxiety disorder: Findings from the irish longitudinal study on ageing," Journal of Affective Disorders, vol. 277, pp. 46-52, 2020.

[51] T. Barnett, A. W. Pearson, R. Pearson, and F. W. Kellermanns, "Five-factor model personality traits as predictors of perceived and actual usage of technology," European Journal of Information Systems, vol. 24, no. 4, pp. 374-390, 2015.

[52] V. Assadi and K. Hassanein, "Continuance intention to use high maintenance information systems: The role of perceived maintenance effort," 2010.

[53] C. S. Carver and J. Connor-Smith, "Personality and coping," Annual review of psychology, vol. 61, pp. 679-704, 2010.

[54] C. Smith, D. W. Organ, and J. P. Near, "Organizational citizenship behavior: Its nature and antecedents," Journal of applied psychology, vol. 68, no. 4, p. 653, 1983.
[55] S. E. Seibert and M. L. Kraimer, "The five-factor model of personality and career success," Journal of vocational behavior, vol. 58, no. 1, pp. 1-21, 2001.

[56] L. Anthony, M. Clarke, and S. Anderson, "Technophobia and personality subtypes in a sample of South African university students," Computers in Human Behavior, vol. 16, no. 1, pp. 31-44, 2000.

[57] A. C. Johnston, M. Warkentin, M. McBride, and L. Carter, "Dispositional and situational factors: influences on information security policy violations," European Journal of Information Systems, vol. 25, no. 3, pp. 231-251, 2016.

[58] S. D. Gosling, P. J. Rentfrow, and W. B. Swann Jr, "A very brief measure of the Big-Five personality domains," Journal of Research in personality, vol. 37, no. 6, pp. 504-528, 2003.

[59] J. F. Hair, C. M. Ringle, and M. Sarstedt, "PLS-SEM: Indeed a silver bullet," Journal of Marketing theory and Practice, vol. 19, no. 2, pp. 139-152, 2011.

[60] W. W. Chin, B. L. Marcolin, and P. R. Newsted, "A partial least squares latent variable modeling approach for measuring interaction effects: Results from a Monte Carlo simulation study and an electronic-mail emotion/adoption study," Information systems research, vol. 14, no. 2, pp. 189-217, 2003.

[61] R. H. Hoyle, Statistical strategies for small sample research. Sage, 1999.

[62] J. F. Hair, J. J. Risher, M. Sarstedt, and C. M. Ringle, "When to use and how to report the results of PLSSEM," European business review, 2019.

[63] C. Liao, J.-L. Chen, and D. C. Yen, "Theory of planning behavior (TPB) and customer satisfaction in the continued use of e-service: An integrated model," Computers in human behavior, vol. 23, no. 6, pp. 2804-2822, 2007.

[64] A. A. Daneji, A. F. M. Ayub, and M. N. M. Khambari, "The Effects of Perceived Usefulness, Confirmation and Satisfaction on Continuance Intention in Using Massive Open Online Course (MOOC)," Knowledge Management \& E-Learning, vol. 11, no. 2, pp. 201214, 2019.

[65] K. M. Alraimi, H. Zo, and A. P. Ciganek, "Understanding the MOOCs continuance: The role of openness and reputation," Computers \& Education, vol. 80, pp. 28-38, 2015.

[66] B. Kim, "The diffusion of mobile data services and applications: Exploring the role of habit and its antecedents," Telecommunications Policy, vol. 36, no. 1, pp. 69-81, 2012.

[67] M. Burisch, "You don't always get what you pay for: Measuring depression with short and simple versus long and sophisticated scales," Journal of Research in Personality, vol. 18, no. 1, pp. 81-98, 1984.

[68] P. T. Costa Jr and R. R. McCrae, "Four ways five factors are basic," Personality and individual differences, vol. 13, no. 6, pp. 653-665, 1992.

[69] L. R. Goldberg, "A broad-bandwidth, public domain, personality inventory measuring the lower-level facets of several five-factor models," Personality psychology in Europe, vol. 7, no. 1, pp. 7-28, 1999. 